\title{
Interspecific competition in Taiwanese corals with special reference to interactions between alcyonaceans and scleractinians
}

\author{
Chang-feng Dai* \\ Department of Biology, Yale University, New Haven, Connecticut 06511, USA
}

\begin{abstract}
Naturally occurring interspecific competition in scleractinian and alcyonacean corals was studied on the reefs of southem Taiwan. A total of 1168 pairwise interactions were recorded and analysis of the data, using a competitive index, led to classification of corals into 5 categories. Three major conclusions can be drawn. (1) The ranking of competitive ability shown by a species bears little apparent relationship to its systematic position, and the most aggressive corals such as Merulina ampliata, Echinophyllia asper, and Mycedium elephantotus are often most abundant on the reefs. (2) Alcyonaceans are generally subordinate when in contact with scleractinians; the former are often subjected to mesenterial digestion by the latter. The position of contact is probably an important determinant in interactions between soft and hard corals. (3) Coral interspecific interactions on the reefs of southern Taiwan show some evidence of competitive networks.
\end{abstract}

\section{INTRODUCTION}

Competition for space between corals on a reef is generally understood to be intense. Although coral competition had been noted much earlier (e.g. Darwin 1842) in the sense that corals sometimes killed their neighbors and overgrew them, its possible ecological significance was not investigated further until the studies by Lang $(1971,1973)$ on the aggressive hierarchy of Atlantic corals. Since then, competition for space among corals has been intensively investigated (e.g. Sheppard 1979, 1980, Wellington 1980, Cope 1981, Bak et al. 1982, Chornesky 1983, Logan 1984).

In comparison to the Caribbean, the interactions of corals on Indo-Pacific reefs are less studied, in part due to the enormous diversity of Indo-Pacific faunas. Scleractinian and alcyonacean corals are abundant sessile invertebrates on Indo-Pacific reefs (Cary 1931, Crossland 1938) in terms of the amount of substratum covered. However, the interactions between these 2 groups have been studied only very recently (e.g. Sammarco et al. 1983, 1985, 1987, La Barre et al. 1986). Previous studies on the interactions between alcyona-

\footnotetext{
- Present address: Institute of Oceanography, National Taiwan University, PO Box 23-13 Taipei, Taiwan, Republic of China
}

cean and scleractinian corals found that alcyonacean corals always win conflicts with scleractinian corals (Benayahu \& Loya 1977, 1981, Sheppard 1979, Nishihira 1981, Coll et al. 1982, Sammarco et al. 1983). Sammarco et al. (1985), however, have provided contradictory evidence that some alcyonacean corals may suffer tissue necrosis when in contact with scleractinian corals. The complexity of the interactions between these 2 groups of organisms indicates that more studies are necessary to clarify their competitive interactions before we can understand the influence on their distribution and relative abundance on coral reefs.

Coral competitive interactions were originally conceived as consistent and hierarchical (Lang 1973, Connell 1976). However, Sheppard (1979) and Bak et al. (1982) have shown that coral interspecific interactions are not completely hierarchical and several factors such as environmental conditions, colony size, position of contact, the development of sweeper tentacles, and the presence of epifauna may alter the result of interactions. The reversal of digestive interactions when sweeper tentacles develop (Wellington 1980) and the inconsistent competitive relationships among coral interactions imply that interspecific competition on a coral reef may be intransitive (Buss \& Jackson 1979, Lang \& Chornesky unpubl.).

The purpose of this study is to investigate the pattern 


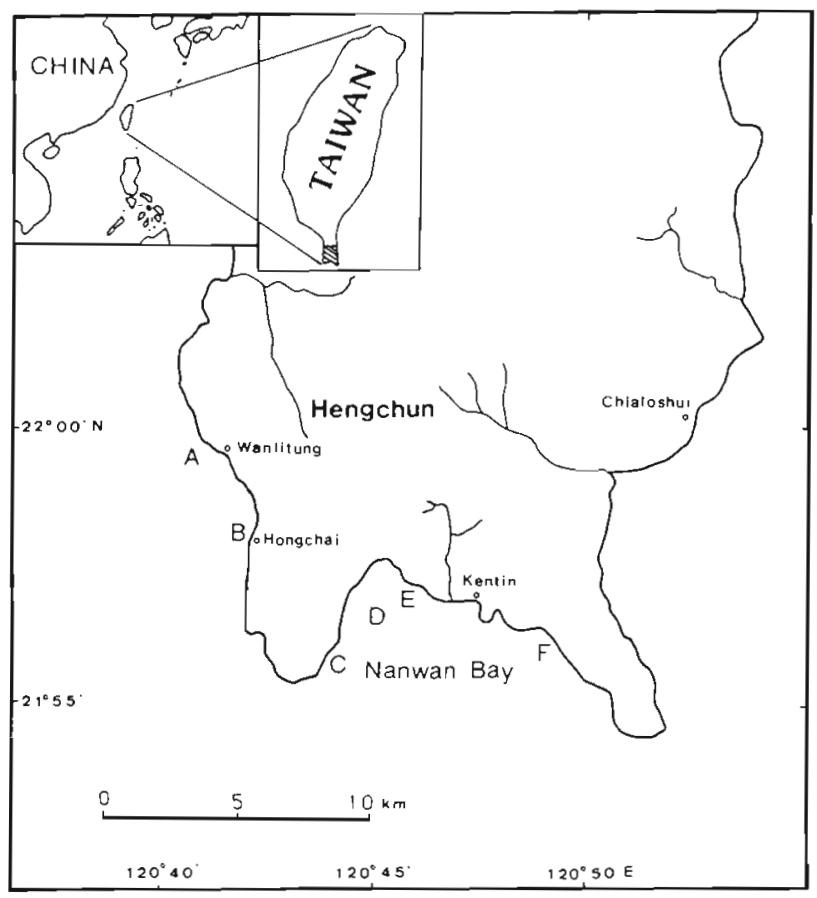

Fig. 1. Study area showing the 6 (A to F) field observation sites

of coral interspecific interactions on the reefs of southern Taiwan. The study surveyed pairwise, naturallyoccurring interactions between any 2 species of scleractinian, alcyonacean, and hydrozoan, with an emphasis on interactions between species of alcyonaceans and scleractinians. The mechanisms and possible effects of interspecific interactions in species diversity and distribution of corals are discussed.

\section{MATERIALS AND METHODS}

Study site. Observations were made at depths between 1 and $30 \mathrm{~m}$ on the fringing reefs of southern Taiwan $\left(21^{\circ} 55^{\prime}\right.$ to $22^{\circ} 00^{\prime} \mathrm{N}, 120^{\circ} 40^{\prime}$ to $120^{\circ} 52^{\prime} \mathrm{E}_{i}$ Fig. 1). Southern Taiwan is located in the middle of the West Pacific Island Arcs. A moderately well-developed fringing reef and relatively high diversity of corals occur in the study area (Jones et al. 1972). Previous work at Hengchun Peninsula has recorded 245 scleractinian coral species and 15 species of alcyonacean corals. A recent systematic study reviewed 218 species of scleractinians and 36 species of alcyonacean corals (Dai 1986). The alcyonacean corals are mainly distributed on both sides of the Peninsula, near the 2 tips, where they often comprise more than half on the surface area covered by coral tissues (Jones et al. 1972 , Dai 1988).

Field observations. Since there are about 250 species of scleractinian and alcyonacean corals on the reefs of southern Taiwan and several thousand pairs of interaction are possible, I restricted this study to naturally occurring interactions. Field observations were made in June to August 1986 and February to April 1987.

Coral colonies that abutted, touched, or were in close proximity $(<8 \mathrm{~cm}$ in distance) to those of another species were recorded along 6 transects. Three types of interactions were recognized: direct interaction, overgrowth, and stand-off. A direct interaction was recognized when a dead margin was observed on one specimen of the pair (Connell 1976). Such scars serve as records of presumed interactions and are easily discernible in the field. Direct interactions may have involved mesenterial digestion, as described by Lang (1973), or sweeper tentacles, as described by Richardson et al. (1979) and Wellington (1980). Since the present study was mainly based on static observations at one particular moment, no effort was made to dinstinguish these or any other presumed mechanisms. Overgrowth was recognized when one specimen grew, physically in contact, over its neighbor but no tissue damage on the contact area was discernible. Many cases of overgrowth accompanied by direct interactions were excluded from this category and classified as direct interactions, since the latter mechanism was perceived to precede the former one. Stand-off represents 2 coral colonies in close contact but with no evidence of tissue damage or overgrowth (Connell 1976, Sheppard 1979).

Data analysis. In order to compare the relative competitive ability of coral species, an index (CI) was calculated for each species based on observations of direct interactions and overgrowth, where

$$
\mathrm{CI}=\frac{\text { No. of wins }- \text { No. of losses }}{\text { Total no. of interactions }}
$$

The calculated $\mathrm{CI}$ for each species can range from -1 for a species which loses all interactions, to +1 for a species which wins all interactions. Species with more than 6 recorded interactions were then grouped into 5 categories according to their competitive abilities (CI). The criteria for this grouping were: aggressive, 1 to 0.6 ; moderately aggressive, 0.59 to 0.2 ; intermediate, 0.19 to -0.2 ; moderately subordinate, -0.21 to -0.6 ; and subordinate, -0.61 to -1 .

\section{RESULTS}

A total of 1168 interactions involving 138 species were recorded. Among these interactions, $533(45.6 \%)$ of them were direct, 443 cases $(37.9 \%)$ involved simple overgrowth, and 184 cases $(15.8 \%)$ were stand-offs. The remaining 8 cases were suspected as being caused 
by allelopathic chemicals. The recorded interactions between major species, with particular reference to alcyonacean/scleractinian interactions, are summarized in Table 1 . The results of grouping of corals based on $\mathrm{Cl}$ are listed in Table 2.

The relative competitive ability of coral species does not have a relationship with their systematic position (Table 2). Species of several large genera, such as Acropora and Montipora, have a wide spread of competitive abilities. Since these genera include species with a variety of growth forms and growth rates which are important in determining the outcome of inter- specific interactions, it is reasonable that they may have different competitive abilities. In general, species of Pectiniidae, Merulinidae and Oculinidae are the most aggressive; species of Mussidae are moderately aggressive; species of Agariciidae and Dendrophylliidae are intermediate; and species of Poritidae (Goniopora excluded) and Alcyoniidae are generally subordinate. The Faviidae display 2 extremes of competitive ability: species of Hydnophora, Platygyra, Favia and Echinopora are aggressive and those of Plesiastrea and Cyphastrea are subordinate. Among the common non-scleractinian reef builders, hydro-

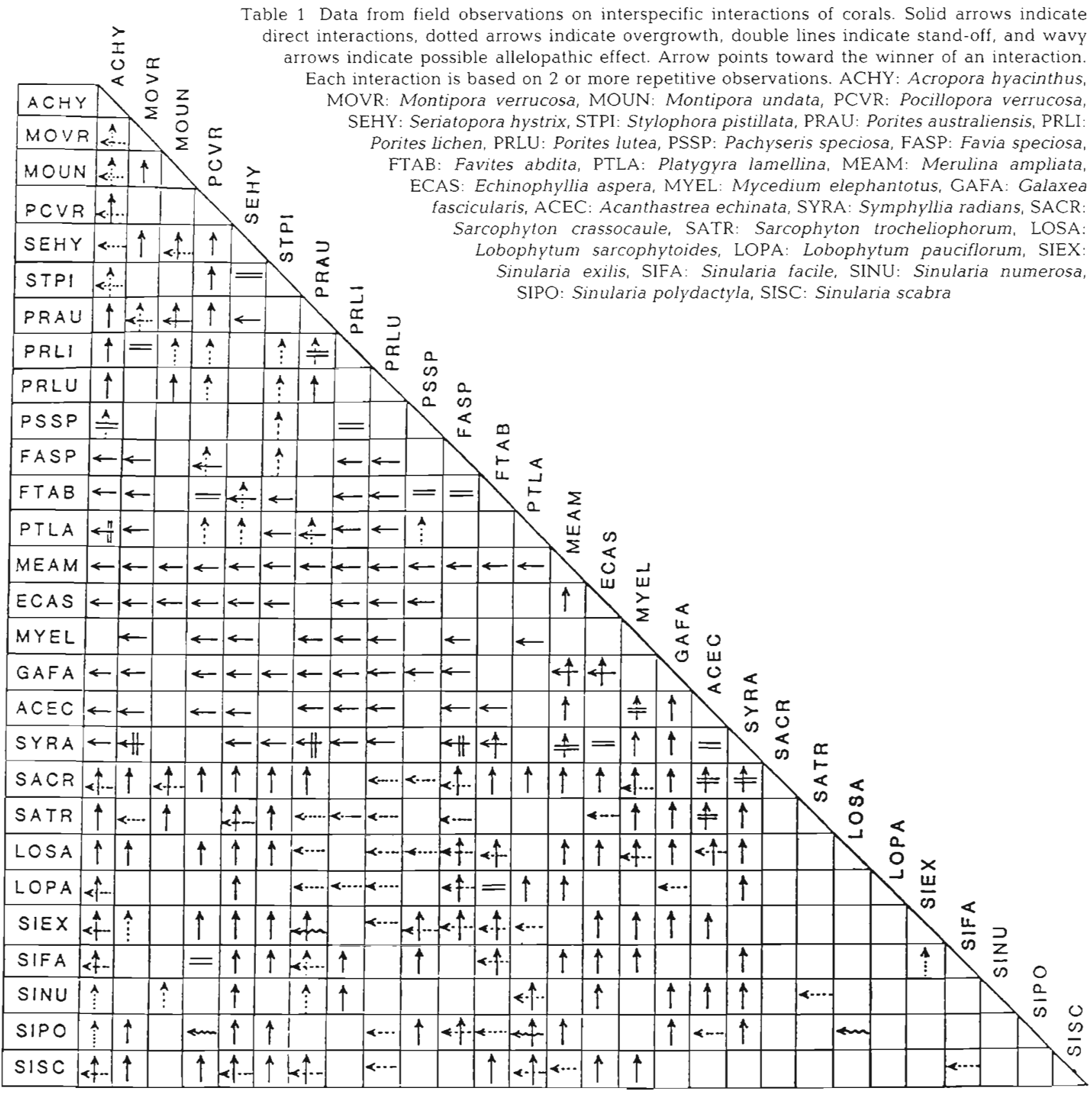




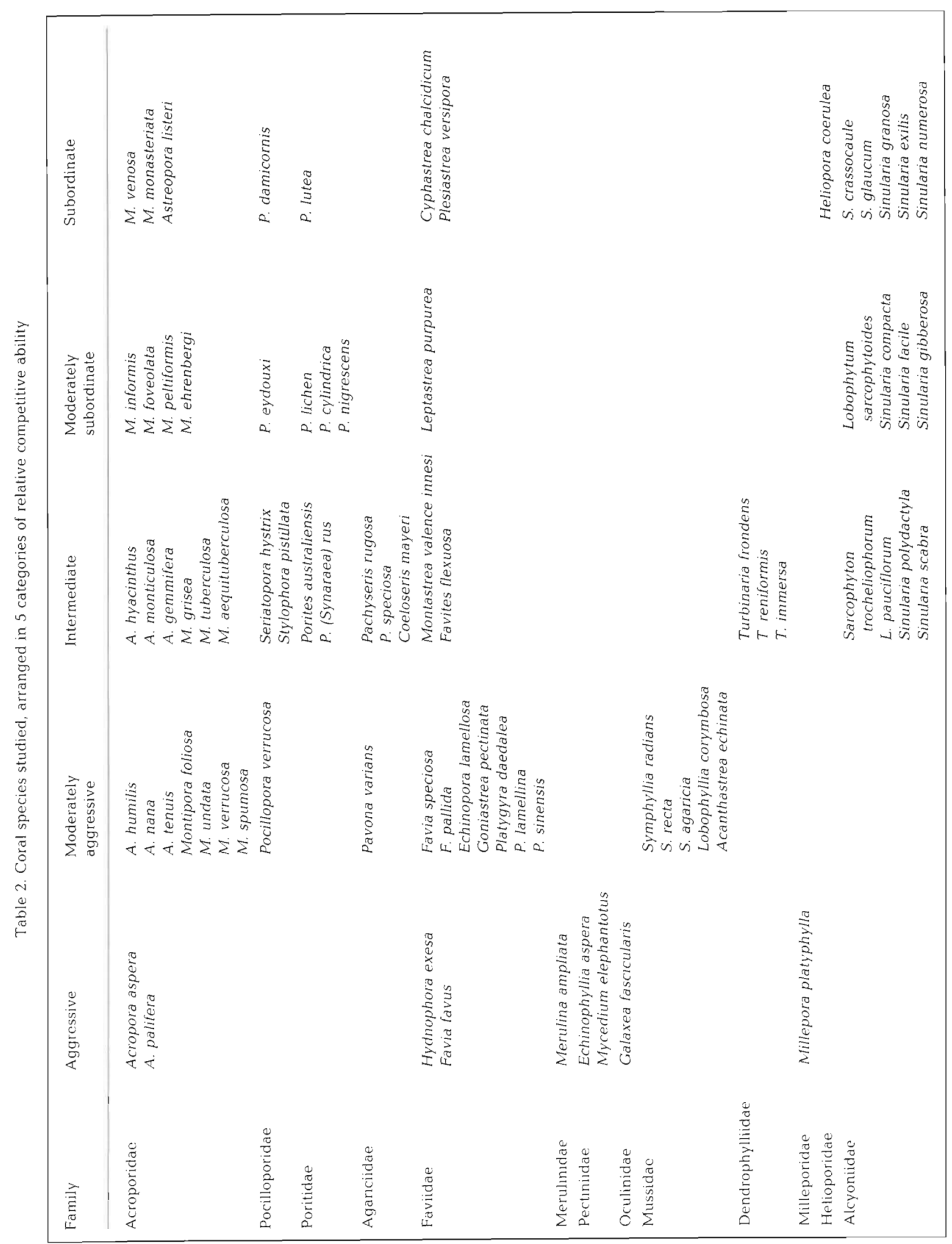


zoans such as Millepora platyphylla are highly aggressive, and the blue alcyonarian Heliopora coerulea, which is killed by all corals encountered, is the most subordinate.

Species of Mussidae, Oculinidae, Pectinidae, Merulinidae and Faviidae often cause severe tissue damage and create a broad polyp-free band on the subordinate species in contact with them. Such polypfree bands might range up to $5 \mathrm{~cm}$ wide and are frequentiy colonized by filamentous algae or macroalgae.

Interactions between alcyonacean and scleractinian corals included colony movement in addition to direct interaction, overgrowth, and stand-off.

In direct interactions, alcyonacean corals are subordinate and frequently suffer from the attacks of scleractinian corals (Table 1). The most abundant species of alcyonaceans in the study area, such as Sarcophyton trocheliophorum, S. crassocaule, Lobophytum sarcophytoides, Sinularia exilis and S. facile, often suffer severe tissue damage when in contact with scleractinian corals. Even the least aggressive species of scleractinians such as Porites spp. and Montipora spp. sometimes can inflict tissue damage on these alcyonaceans. The most aggressive scleractinians such as Galaxea fascicularis and Goniopora sp. often extrude sweeper tentacles or sweeper polyps to attack adjacent alcyonaceans (Fig. 2).

Alcyonaceans sometimes overgrow scleractinians, especially the less aggressive species and massive or encrusting forms. In all cases of overgrowth, alcyonacean polyp-bearing capitula lie above the scleractinians and the sterile stalks of the former abut against the scleractinian colonies.

Interactions mediated by presumed allelochemicals were difficult to detect in field observations. In 8 interactions, significant tissue necrosis in scleractinians was observed and this was suspected to be caused by allelopathic chemicals.

Five cases of colony movement of alcyonaceans over scleractinians (La Barre \& Coll 1982) were recorded when colonies of Nephthea erecta moved across the surface of Acropora hyacinthus by continuous colony division (Fig. 3).

\section{DISCUSSION}

Since more than 100 species of scleractinians and alcyonaceans were involved in this study and the interactions are highly complicated, it is not possible to establish a clear-cut hierarchy as achieved by Lang (1973) and Cope (1981). The grouping of Taiwanese scleractinian corals according to their competitive abilities (Table 2) is mostly in agreement with Sheppard (1979) and Cope (1981) but includes many more species. Sheppard (1979) concluded that Seriatopora hystrix was very subordinate and Acropora hyacinthus was highly aggressive. In this study, however, they

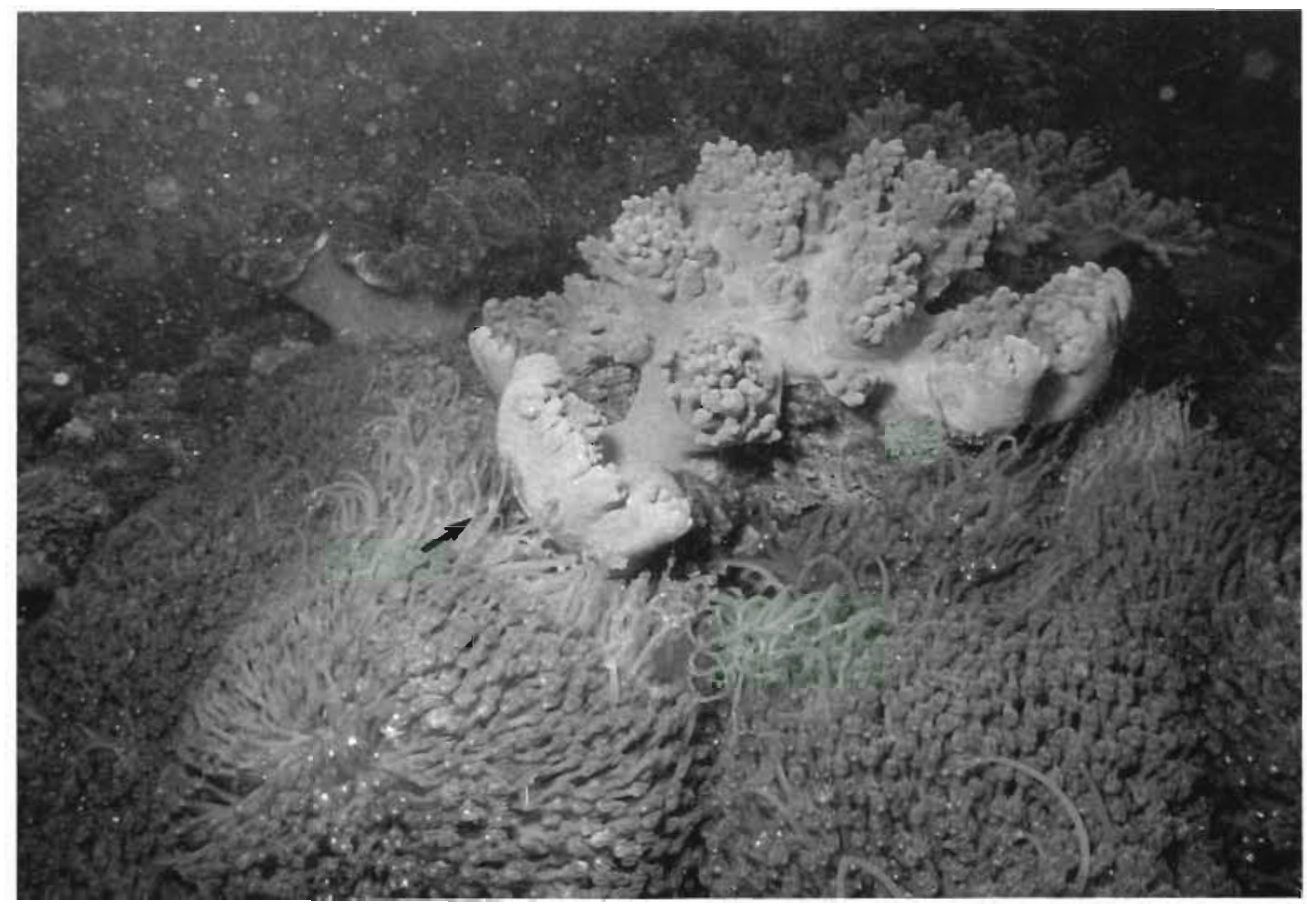

Fig. 2. Goniopora sp. (Poritidae: Scleractinia) extends its 'sweeper polyps' attacking an alcyonacean coral, Sinularia $\mathrm{sp} .(\times 0.3)$ 


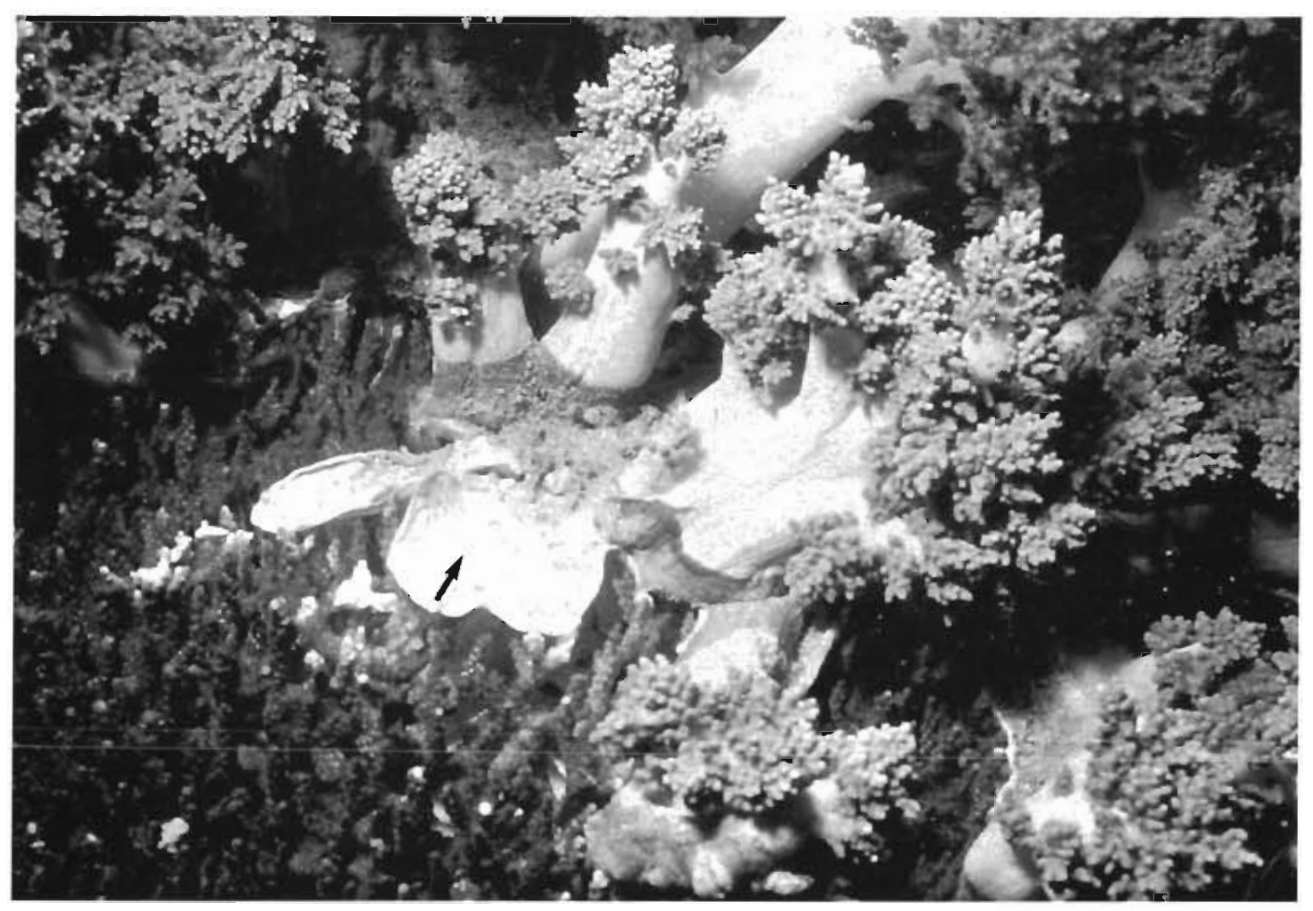

Fig. 3. Nephthea erecta (Nephtheidae: Octocorallia) colonies overgrowing a scleractinian coral, Acropora hyacinthus, by continuous colony division. Note the trails of $N$. erecta $(\times 0.6)$

were intermediate and won about half of the interactions.

The alcyonacean corals on the reefs of southern. Taiwan are generally subordinate when in contact with scleractinian corals. Previous studies on competitive strategies of alcyonacean corals have emphasized the effects of allelopathic chemicals (Coll et al. 1982, Sammarco et al. 1983, 1985) and their ability to overgrow opponents (Benayahu \& Loya 1977, 1981, Nishihira 1981 ) in competition for space on corals reefs. Since the deleterious effects demonstrated by Sammarco et al. (1983) were rarely observed in this study, chemicals may not be of great importance for alcyonaceans in competition for space on the reefs of southern Taiwan.

In the Caribbean, the most aggressive species (Mussidae, Meandrinidae, and Faviidae) are often massive Since they grow relatively slowly, they are not good space competitors and they are minor components of coral communities (Lang 1973). On the other hand, in the Indo-Pacific, the most aggressive species (Merulinidae, Pectiniidae) often have a better ability to overgrow other species. Hence, they are efficient space competitors and are major components of coral communities (Sheppard 1982).

Since several mechanisms are involved in coral interactions and a number of factors may influence the outcome of these interactions, scleractinian and alcyonacean coral interspecific interactions on a reef are likely intransitive. The competitive networks are likely to be formed by interactions between alcyonacean and scleractinian corals. Since alcyonaceans are among the major sessile organisms on Indo-Pacific reefs, the significance of competitive networks should not be neglected.

Acknowledgements. I thank the advisory committee for my Ph. D., L. W. Buss, C. Craig, W. D. Hartman and J. Lang, for their advice and helpful criticism of the manuscript. I am grateful to Mr Y'unchun Tsai for his assistance with field work. The coral specimens of this study have been deposited in the Peabody Museum of Natural History, Yale University, New Haven, Connecticut. USA and Institute of Oceanography, National Taiwan University, Taipei, Taiwan. This study was supported by a fellowship from the Graduate School of Yale University and a grant from the National Science Council, R.O.C. (NSC-78-0209-B002a-04). The manuscript was greatly improved by critical readings by Dr S. La Barre and 2 anonymous reviewers

\section{LITERATURE CITED}

Bak, R. P. M., Termaat, R. M., Dekker, R. (1982). Complexity of coral interactions: influence of time, location of interaction and epifauna. Mar. Biol 69: 215-222

Benayahu, Y., Loya, Y. (1977). Space partitioning by stony corals, soft corals and benthic algae on the coral reef of the northern Gulf of Eilat (Red Sea). Helgolander wiss. Meeresunters. 30: 362-382

Benayahu, Y., Loya, Y. (1981). Competition for space among coral-reef sessile organisms at Eilat, Red Sea. Bull. mar Sci. 31:514-522 
Buss, L. W., Jackson, J B. C. (1979). Competitive networks: nontransitive competitive relationships in cryptic coral reef environments. Am. Nat. 113: 223-234

Cary, L. R. (1931). Studies on the coral reefs of Tutuila, American Samoa with special reference to the Alcyonaria. Pap. Dep. mar Biol. Carnegie Instn Wash. 27: 53-98

Chornesky, E. A. (1983). Induced development of sweeper tentacles on the reef coral Agaricia agaricites: a response to direct competition. Biol. Bull. mar. biol. Lab., Woods Hole 165: 569--581

Coll, J. C., La Barre, S., Sammarco, P. W., Williams, W T., Bakus, G. J. (1982). Chemical defenses in soft coral (Coelenterata: Octocorallia) of the Great Barrier Reef: a study of comparative toxicities. Mar Ecol. Prog. Ser 8: $271-278$

Connell, J. H. (1976). Competitive interactions and the species diversity of corals. In: Mackie, G. O. (ed.) Coelenterate ecology and behavior Plenum Press, New York, p. 51-58

Cope, M. (1981). Interspecific coral interactions in Hong Kong. Proc. 4th int Coral Reef Symp. 2: 357-362

Crossland. C. (1938). The coral reefs at Ghardaqa, Red Sea. Proc. zool. Soc. Lond. A 108: 513-523

Dai, C. F. (1986). Systematics and ecology of corals in the Kentin National Park area. Conservation Report No. 30 , The Kenting National Park Headquarters, Taiwan (in Chinese)

Dai, C. F. (1988). Community ecology of corals on the fringing reefs of Taiwan. Ph.D. thesis, Yale tniversity

Darwin, C. R. (1842). The structure and distribution of coral reefs. Reprinted by the University of Arizona Press, Tucson, (1984)

Jones, O. A., Randall, R. H., Cheng, Y M., Kami, H. T., Mak, S. M. (1972). A marine biological survey of southern Taiwan with emphasis on corals and fishes. Inst. Oceanogr., Nat. Taiwan Univ., Spec. Publ. No. 1,93 pp.

La Barre, S., Coll, J. C. (1982). Movement in soft corals: an interaction between Nephthea brassica (Coelenterata: Octocorallia) and Acropora hyacinthus (Coelenterata: Scleractinia). Mar Biol. 72: 119-124

La Barre, S., Coll, J. C., Sammarco, P. W. (1986). Competitive

This article was submitted to the editor strategies of soft corals (Coelenterata: Octocorallia): III. Spacing and aggressive interactions between alcyonaceans. Mar Ecol. Prog. Ser 28: 147-156

Lang, J. (1971). Interspecific aggression by scleractinian corals. 1. The rediscovery of Scolymia cubonsis (MilneEdwards and Haime). Bull. mar. Sci. 21: 952.959

Lang, J. (1973). Interspecific aggression by scleractinian corals. 2. Why the race is not only to the swift. Bull. mar Sci. 23: $261-279$

Logan, A. (1984). Interspecific aggression in hermatypic corals from Bermuda. Coral Reefs 3: 131-138

Nishihira, M. (1981). Interaction of alcyonaria with hermatypic corals on an Okinawa reef flat. Proc. 4th Int. Coral Reef Symp. 1722

Richardson, C. A., Dustan, P., Lang, J. C. (1979). Maintenance of living space by sweeper tentacles of Montastraea cavernosa, a Caribbean reef coral. Mar Biol. 55: 181-186

Sammarco, P. W., Coll, J. C., La Barre, S. (1985). Competitive strategies of soft corals (Coelenterata: Octocorallia). II. Variable defensive responses and susceptibility to scleractinian corals. J. exp. mar. Biol. Ecol. 91 199-215

Sammarco, P. W., coll, J. C., La Barre, S., Willis, B. (1983). Competitive strategies of soft corals (Coelenterata: Octocorallia): allelopathic effects on selected scleractinian corals. Coral Reefs 1. 173-178

Sammarco, P. W., La Barre, S., Coll, J. C. (1987). Defensive strategies of soft corals (Coelenterata: Octocorallia) of the Great Barrier Reef. III. The relationship between ichthyotoxicity and morphology. Oecologia (Berl.) 74: 93-101

Sheppard, C. R. C. (1979). Interspecific aggression between reef corals with reference to their distribution. Mar Ecol. Prog. Ser 1. 237-247

Sheppard, C. R. C. (1980). Coral cover, zonation and diversity on reef slopes of Chagos atolls, and population structures of the major species. Mar. Ecol. Prog. Ser. 2: 193-205

Sheppard, C. R. C. (1982). Coral populations on reef slopes and their major controls. Mar Ecol. Prog. Ser 7: 83-115

Wellington, G. M. (1980). Reversal of digestive interactions between Pacific reef corals: mediation by sweeper tentacles. Oecologia (Berl.) 47: 340-343

Manuscript first received: June 16, 1989

Revised version accepted: November 27, 1989 